\title{
$\alpha$-Helical Antimicrobial Peptide Encapsulation and Release from Boron Nitride Nanotubes: A Computational Study
}

\author{
Maryam Zarghami Dehaghani \\ Farrokh Yousefi (iD) ${ }^{2}$ \\ Babak Bagheri iD ${ }^{3}$ \\ Farzad Seidi ${ }^{1}$ \\ Amin Hamed Mashhadzadeh (iD) ${ }^{4}$ \\ Navid Rabiee (ID ${ }^{5}$ \\ Payam Zarrintaj $^{6}$ \\ Ebrahim Mostafavi iD ${ }^{7,8}$ \\ Mohammad Reza Saeb ${ }^{4}$ \\ Yeu-Chun $\mathrm{Kim}^{3}$ \\ 'Jiangsu Co-Innovation Center of Efficient \\ Processing and Utilization of Forest \\ Resources and Joint International Research \\ Lab of Lignocellulosic Functional Materials, \\ Nanjing Forestry University, Nanjing, 210037, \\ People's Republic of China; ${ }^{2}$ Department of \\ Physics, University of Zanjan, Zanjan, 45195- \\ 313, Iran; ${ }^{3}$ Department of Chemical and \\ Biomolecular Engineering, Korea Advanced \\ Institute of Science and Technology (KAIST), \\ Daejeon, 305-70I, Republic of Korea; \\ ${ }^{4}$ Center of Excellence in Electrochemistry, \\ School of Chemistry, College of Science, \\ University of Tehran, Tehran, Iran; \\ ${ }^{5}$ Department of Chemistry, Sharif University \\ of Technology, Tehran, I I 155-35 I6, Iran; \\ ${ }^{6}$ School of Chemical Engineering, Oklahoma \\ State University, Stillwater, OK, 74078, USA; \\ ${ }^{7}$ Stanford Cardiovascular Institute, Stanford \\ University School of Medicine, Stanford, CA, \\ USA; ${ }^{8}$ Department of Medicine, Stanford \\ University School of Medicine, Stanford, \\ CA, USA
}

Correspondence: Ebrahim Mostafavi Stanford Cardiovascular Institute, Stanford University School of Medicine, Stanford, CA, USA

Email ebimsv@stanford.edu

Amin Hamed Mashhadzadeh

Center of Excellence in Electrochemistry, School of Chemistry, College of Science, University of Tehran, Tehran, I4I55-6455, Iran

Email amin.hamed.m@gmail.com
Introduction: Antimicrobial peptides are potential therapeutics as anti-bacteria, antiviruses, anti-fungi, or anticancers. However, they suffer from a short half-life and drug resistance which limit their long-term clinical usage.

Methods: Herein, we captured the encapsulation of antimicrobial peptide HA-FD-13 into boron nitride nanotube (BNNT) $(20,20)$ and its release due to subsequent insertion of BNNT $(14,14)$ with molecular dynamics simulation.

Results: The peptide-BNNT $(20,20)$ van der Waals (vdW) interaction energy decreased to $-270 \mathrm{kcal} \cdot \mathrm{mol}^{-1}$ at the end of the simulation (15 ns). However, during the period of $0.2-1.8$ $\mathrm{ns}$, when half of the peptide was inside the nanotube, the encapsulation was paused due to an energy barrier in the vicinity of BNNT and subsequently the external intervention, such that the self-adjustment of the peptide allowed full insertion. The free energy of the encapsulation process was $-200.12 \mathrm{kcal} \cdot \mathrm{mol}^{-1}$, suggesting that the insertion procedure occurred spontaneously.

Discussion: Once the BNNT $(14,14)$ entered into the BNNT $(20,20)$, the peptide was completely released after 83.8 ps. This revealed that the vdW interaction between the BNNT $(14,14)$ and BNNT $(20,20)$ was stronger than between BNNT $(20,20)$ and the peptide; therefore, the BNNT $(14,14)$ could act as a piston pushing the peptide outside the BNNT $(20,20)$. Moreover, the sudden drop in the vdW energy between nanotubes to the value of the $-1300 \mathrm{Kcal} \cdot \mathrm{mol}^{-1}$ confirmed the self-insertion of the BNNT $(14,14)$ into the BNNT $(20,20)$ and correspondingly the release of the peptide.

Keywords: drug delivery, boron nitride nanotubes, molecular dynamics simulation, drug release, antimicrobial peptide

\section{Introduction}

Peptides are oligomers of short-chain amino acid sequences interconnected by amide or peptide bonds formed through dehydration condensation reaction. ${ }^{1,2}$ They are generally classified into four main groups based on their structures, including $\alpha$-helical, $\beta$-sheet, the extended structures, and loops. ${ }^{3}$ The desired peptides for a given target having tailored chemical structures and activities can be obtained through appropriate genetics and chemical engineering. ${ }^{4}$ Depending on their microstructure and functional groups, ${ }^{5}$ diverse peptides have been developed for various applications in biomedicine, ${ }^{6}$ bioengineering, and nanotechnology. ${ }^{7,8}$ Because of their highly selective character and being relatively safe, peptides have been widely considered in pharmaceutical research. ${ }^{9}$ 
Bioactive peptides are a class of peptides that largely contribute to biological processes and have considerable physiological health benefits. ${ }^{10}$ They may act as hormones or drugs given their activities, such as anti-oxidative, mineral binding, anti-hypertensive, antimicrobial, antithrombotic, and immunomodulatory. ${ }^{11-13}$ Antimicrobial peptides have emerged as anti-infective drugs with the ability to protect living organisms against the invasion of pathogens. ${ }^{14}$ The antimicrobial activities of these peptides depend on their features, such as their charge, hydrophobicity, chain conformation, and polar angle. ${ }^{15-17}$ However, most antimicrobial peptides possess an amphipathic structure; they are cationic at physiological $\mathrm{pH}$ and accumulate onto and subsequently cause the disintegration or permeabilization of the bacterial membrane. ${ }^{18,19}$ These antimicrobial peptides edge over conventional antibiotics because of their broad range of antimicrobial activities (anti-bacteria, anti-viruses, anti-fungi, and anti-cancers) and their lower drug resistance. ${ }^{20}$

Besides the advantages mentioned above for antimicrobial peptides, some drawbacks such as short half-life, toxicity, hemolytic activity, drug resistance, and the blood-brain barrier would limit their long-term usage in clinical applications. ${ }^{21-23}$ For example, the antimicrobial peptide indolicidin rich with tryptophan would lead to hemolytic anemia, despite providing a broad antimicrobial activity window. ${ }^{24}$ As another example, gram-negative bacterial pathogens (CAMPS) would resist cationic antimicrobial peptides through surface remodeling (polysaccharide modification, phospholipid modification, and capsule production), forming biofilms, efflux pumps, proteolytic degradation, binding and sequestering CAMPs, and modulation of CAMP expression. ${ }^{25}$ In this sense, nano-based drug delivery systems have been introduced and practiced to overcome barriers and thereby support peptide-based therapy by preventing antimicrobial drug resistance, ${ }^{26,27}$ sustain and target drug release, ${ }^{28,29}$ facilitating the penetration of the drug into the cells, bacteria, and tissues, ${ }^{30}$ and drug protection from oxidization, destructive reactions, and environmental tension. ${ }^{31}$

Boron nitride nanotubes (BNNT)-based drug delivery systems have attracted considerable attention as nanocarriers due to their distinct features such as their large interior volume adequate for drug encapsulation, ${ }^{32,33}$ their ability to surface functionalization for targeted delivery, ${ }^{28,29}$ non-toxicity, and biocompatibility. ${ }^{34,35}$ Several theoretical reports have addressed the performance of BNNT as a drug carrier. Table 1 summarizes the research performed on BNNT playing the role of drug carrier. For instance, Mirhaji et al studied the effect of water/ethanol ratio on the encapsulation process of the anticancer drug of docetaxel inside the Armchair BNNT $(13,13)$ utilizing molecular dynamics (MD) simulation. ${ }^{36}$ The Lennard-Jones energies calculated for the systems of BNNT-docetaxel attained at water/ethanol ratio of $60 \%$, and $75 \%$ were 0 and $-239 \mathrm{kcal} \cdot \mathrm{mol}^{-1}$, respectively. Moreover, van der Waals (vdW) interaction between docetaxel and the BNNT took minimum at these ratios. Likewise, Khatti and Hashemianzadeh captured the penetration rate of the platinum drug into the BNNT and the functionalized BNNT with 18 hydroxyl groups on one edge. ${ }^{37}$ The hydroxyl groups facilitated the encapsulation of platinum into BNNT cavity through both hydrogen bonding and the van der Waals interaction between the drug and functionalized BNNT. Similar behavior is reported for the encapsulation of gemcitabine inside BNNT $(18,0)$ by Roosta et al. ${ }^{38}$ MD simulation proved spontaneous insertion of the drug into the cavities of the BNNT, featured by a negative $\mathrm{vdW}$ interaction energy value of $-46.1 \mathrm{kcal} \cdot \mathrm{mol}^{-1}$. They also quantified the release performance of encapsulated gemcitabine using fullerene $\left(\mathrm{C}_{60}\right)$, which resulted in a total potential energy difference of $-140.1 \mathrm{kcal} \mathrm{mol}^{-1}$.

Theoretical investigations on the BNNT-drug systems proved the presence of non-bonded interaction energies such as vdW and electrostatic interactions between the drug and BNNT supporting the encapsulation and release processes. The MD simulation, in this regard, is a promising tool that has been widely applied to investigate the performance of complex nano-sized systems bridging diverse areas of cell biology and materials science. ${ }^{48,49}$ Besides the great ability that the MD offers to evaluate the thermal and mechanical features of nanostructures. ${ }^{50-55}$ The 13-amino acid peptide (named HA-FD-13) with the ID code of 2124 (chosen from protein data bank (https://www.rcsb.org/structure/2L24)) is an $\alpha$ Helical antimicrobial peptide ( $\alpha$-AMP) derived from the fusion domain (FD) of the hemagglutinin (HA) of the influenza virus. This antimicrobial peptide has the positive charge needed for penetration into the anionic microbial membranes. ${ }^{56}$ However, like other kinds of antibiotics, drug resistance arising from long-term and overdose drug usage would limit its repeated usage. Therefore, the AMPnanocarrier complexes are used to overcome this obstacle. In the present work, the MD simulation was applied to model and pattern the encapsulation process of $\alpha$-AMP 
Table I The Summary of the Researches Performed on Evaluation of BNNT as Drug Carrier in Water at 300K and Iatm

\begin{tabular}{|c|c|c|c|}
\hline Author & Simulated System & Method & Calculated Energy \\
\hline Mortazavifar et al ${ }^{39}$ & Hydroxyurea $(\mathrm{HU})$ drug into BNNT $(6,6)$ & $\begin{array}{l}\text { MD } \\
\text { DFT }\end{array}$ & $\begin{array}{l}\text { Adsorption energy }=-34.36 \mathrm{~kJ} \mathrm{~mol}{ }^{-1} \\
\text { Interaction energy }=-130.73 \mathrm{~kJ} \mathrm{~mol}^{-1} \\
\text { Deformation energy }=96.37 \mathrm{~kJ} \mathrm{~mol} \\
\mathrm{vdW} \text { energy between } \mathrm{HU} \text { and BNNT=-20 kJ mol }\end{array}$ \\
\hline Roosta et $\mathrm{al}^{40}$ & Cisplatin drug into BNNT & $\begin{array}{l}\text { DFT } \\
\text { Monte } \\
\text { carlo }\end{array}$ & $\begin{array}{l}\mathrm{vdW} \text { energy }=12.84 \mathrm{kcal} \cdot \mathrm{mol}^{-1} \\
\text { Solvation free energy of drug-BNNT }=-4.128 \mathrm{kcal} \mathrm{mol}^{-1} \\
\text { Electrostatic energy }=-2803.992 \mathrm{Kcal} \cdot \mathrm{mol}^{-1}\end{array}$ \\
\hline $\begin{array}{l}\text { Hasanzade and } \\
\text { Raissi }^{41}\end{array}$ & $\begin{array}{l}\text { 6-Thioguanine on BNNT with length and } \\
\text { diameter of about } 13.64 \text { and } 5.14 \AA\end{array}$ & DFT & $\begin{array}{l}\text { Adsorption energy }=-47.3 \mathrm{I} \mathrm{Kj} \cdot \mathrm{mol}^{-1} \\
\text { Deformation energy of BNNT= } 179.4 \mathrm{I} \mathrm{kJ} \mathrm{mol}^{-1} \\
\text { Solvation energy }=-142.53 \mathrm{~kJ} \mathrm{~mol}^{-1} \\
\text { Deformation energy of drug }=88.18 \mathrm{Kj} \cdot \mathrm{mol}^{-1}\end{array}$ \\
\hline Zarghami et $\mathrm{al}^{33}$ & Protein SmtA into BNNT $(28,28)$ & MD & $\begin{array}{l}\mathrm{vdW} \text { energy between protein and } \mathrm{BNNT}=-189.63 \mathrm{kcal} \mathrm{mol}^{-1} \\
\text { Free energy of the protein }=-160 \mathrm{kcal} \mathrm{mol}^{-1} \text { Potential energy of } \\
\text { the protein }=-1900 \mathrm{kcal} \mathrm{mol}^{-1}\end{array}$ \\
\hline Zarghami et $\mathrm{al}^{42}$ & The peptide cRW3 into BNNT $(12,12)$ & MD & $\begin{array}{l}\mathrm{vdW} \text { energy between protein and } \mathrm{BNNT}= \\
-142.7 \mathrm{kcal} \mathrm{mol}^{-1} \\
\text { Free energy of the protein }=-90 \mathrm{kcal} \mathrm{mol}^{-1} \\
\text { Potential energy of the peptide }=-50 \mathrm{kcal} \mathrm{mol}^{-1}\end{array}$ \\
\hline $\begin{array}{l}\text { Iranmanesh-Zarandy } \\
\text { and Dehestani }{ }^{43}\end{array}$ & $\begin{array}{l}\text { Paracetamol Drug on BNNT }(10,10) \text {, } \\
\text { length }=2.2 \mathrm{~nm}\end{array}$ & MD & $\begin{array}{l}\text { Free energy }=-1085.91 \mathrm{~kJ} \cdot \mathrm{mol}^{-1} \\
\mathrm{vdW} \text { energy between drug and BNNT= }-239.219 \mathrm{~kJ} \cdot \mathrm{mol}^{-1} \\
\text { Lennard-Jones energy }=-2000 \mathrm{~kJ} \mathrm{~mol}{ }^{-1} \\
\text { Bonded energy }=-973.56 \mathrm{~kJ} \mathrm{~mol}{ }^{-1} \\
\text { Binding free energy }=-67.06 \mathrm{~kJ} \mathrm{~mol}{ }^{-11}\end{array}$ \\
\hline Sedghamiz et al ${ }^{44}$ & Mechlorethamine drug into BNNT $(10,0)$ & MD & $\begin{array}{l}\text { Total energy }=-7500 \mathrm{kcal} \cdot \mathrm{mol}^{-1} \\
\mathrm{vdW} \text { energy }=1700 \mathrm{kcal} \cdot \mathrm{mol}^{-1} \\
\text { Electrostatic energy }=-10,550 \mathrm{kcal} \cdot \mathrm{mol}^{-1}\end{array}$ \\
\hline Roosta et $\mathrm{al}^{38}$ & Gemcitabine in BNNT $(18,0)$ & MD & $\begin{array}{l}\text { Total potential energy }=-948.3 \mathrm{kcal}^{-\mathrm{mol}^{-1}} \\
\text { Internal energy }=-905.7 \mathrm{kcal} \cdot \mathrm{mol}^{-1} \\
\text { Non-bond energy }=-42.5 \mathrm{kcal} \cdot \mathrm{mol}^{-1} \\
V d W \text { energy between drug and BNNT }=-42.2 \mathrm{kcal} \cdot \mathrm{mol}^{-1} \\
\text { Electrostatic energy between drug and BNNT }=-0.4 \mathrm{kcal} \cdot \mathrm{mol}^{-1}\end{array}$ \\
\hline El Khalifi et $\mathrm{al}^{45}$ & Carboplatin drug in BNNT $(10,10)$ & MD & $\begin{array}{l}\text { The changes of Interaction enrgy between BNNT and water } \\
\text { during the insertion of the drug into the BNNT }=650 \mathrm{kcal} \mathrm{mol}^{-1}\end{array}$ \\
\hline Mirhaji et $\mathrm{al}^{36}$ & Docetaxel drug in BNNT $(13,13)$ & MD & $\begin{array}{l}\text { Potential energy }=-700,000 \mathrm{kcal} \cdot \mathrm{mol}^{-1} \\
\text { Lennard-Jones energy }=-150 \mathrm{kcal} \cdot \mathrm{mol}^{-1}\end{array}$ \\
\hline $\begin{array}{l}\text { Khatti and } \\
\text { Hashemianzadeh }\end{array}$ & Platinum drug in $\mathrm{BNNT}(40,0)$, length $=14 \AA$ & MD & $\begin{array}{l}\mathrm{vdW} \text { energy }=-43 \mathrm{kcal} \mathrm{mol}^{-1} \\
\text { Electrostatic energy }=0.018 \mathrm{kcal} \mathrm{mol}^{-1}\end{array}$ \\
\hline Mehrjouei et $\mathrm{al}^{46}$ & Cisplatin in BNNT $(12,12)$ & MD & $\begin{array}{l}\mathrm{vdW} \text { energy }=-\mathrm{kcal} \cdot \mathrm{mol}^{-1} \\
\text { Electrostatic energy }=-55 \mathrm{kcal} \cdot \mathrm{mol}^{-1} \\
\text { Total energy }=-62 \mathrm{kcal} \cdot \mathrm{mol}^{-1}\end{array}$ \\
\hline Saikia et $\mathrm{al}^{47}$ & The protein Pyrazinamide on BNNT $(5,5)$ & $\begin{array}{l}\text { MD } \\
\text { DFT }\end{array}$ & Adsorption energy $=-0.854 \mathrm{eV}$ \\
\hline
\end{tabular}


inside the BNNT $(20,20)$ by calculating the vdW interactions between the BNNT and the peptide. Computational analyses were based on the potential of mean force (PMF) of the encapsulated peptide. Then, the release behavior of the encapsulated peptide in the presence of the BNNT $(14,14)$, a releasing agent which acts as piston pushing out the peptide from BNNT $(20,20)$, was evaluated by computing the distances between the center of mass (CoM) of the peptide and nanotubes and vdW interaction energy between the BNNT $(14,14)$ and BNNT $(20,20)$.

\section{Simulation Method}

In the present study, MD simulation of the encapsulation and release processes of the peptide HA-FD-13 into and from the BNNT was performed through the Large-Scale Atomic/Molecular Simulator (LAMMPS) software ${ }^{57}$ by applying CHARMM27 force field. ${ }^{58}$ Tersoff potential was used to consider the interaction between boron and nitrogen atoms of nanotubes. ${ }^{59}$ The partial charge of the $\mathrm{B}$ and $\mathrm{N}$ atoms are 1 and -1 , respectively. Here the BNNT was neutralized, and the total charge was approximately zero. The temperature and the pressure of the systems were adjusted to about $300 \mathrm{~K}$ and $101.3 \mathrm{KPa}$ through applying NPT Ensemble. The inner and outer cutoff distances for the Lennard-Jones potential and Coulombic potential were considered 8 and $12 \dot{\mathrm{A}}$, respectively. Lennard-Jones' parameters for cross vdW interactions between non-bonded atoms were estimated using Lorentz-Berthelot combination rule. ${ }^{60}$ The visualization was obtained using visual molecular dynamics (VMD). ${ }^{61}$ The $\alpha$-Helical antimicrobial peptide ( $\alpha$-AMP) named HAFD-13 (containing amino acids ILE-PHE-GLY-ALA-ILEALA-GLY-PHE-ILE-LYS-ASN-ILE-TRP-NH2) with the ID code of 2124 was chosen from the protein data bank. This antimicrobial peptide has a positive charge so that it can penetrate the anionic microbial membranes. The simulation steps of this research are described as following:

1) At the first step, the insertion process of the peptide HA-FD-13 into the BNNT and subsequently the stability of encapsulated peptide HA-FD-13 in BNNT was studied. Considering the size of HA-FD-13, the BNNT with chirality of armchair $(20,20)$ and the length and diameter of 40 $\dot{\mathrm{A}}$ and $27.14 \dot{\mathrm{A}}$, respectively, have been selected as a nanocarrier according to the size of the antimicrobial peptide, which means that the minimum possible size of the BNNT was chosen so that the peptide would be encapsulated in the cavity of the nanotube beside the capability of the BNNT to penetrate cells. At the beginning of this simulation, the peptide HA-FD-13 was situated at the initial distance of $2 \dot{A}$ from the nanotube. The axial direction of the nanotube was parallel to the z-axis of the simulation box. The complex of BNNT/HA-FD-13 was immersed in the simulation box consisting of TIP3P water molecules and counter-ions to neutralize the simulated solution with periodic boundary conditions. To assess the peptide's encapsulation process, in the first stage, the system's minimization was done while the nanotube and the peptide were fixed. Second, the system was relaxed in the NPT Ensemble at $300 \mathrm{~K}$. Next, the MD runs were performed in the NVT ensemble for $15 \mathrm{~ns}$ with the time step of $1 \mathrm{fs}$ while the nanotube and nanotube and the peptide were fixed and unfixed, respectively. The vdW interaction between the peptide HA-FD-13 and the BNNT was calculated according to the below equality as: ${ }^{61}$

$$
E_{v d W-\text { int }}(t)=E_{\text {peptide }+B N N T}(t)-\mathrm{E}_{\text {peptide }}(t)-E_{B N N T}(t)
$$

where $E_{v d W-i n t}$ refers to vdW energy between HA-FD -13 and the nanotube, $E_{\text {peptide }+B N N T}$ is $\mathrm{vdW}$ interaction of HA-FD-13 combined with the BNNT. $E_{\text {peptide }}$ and $E_{B N N T}$ stand for vdW energies of HA-FD-13 and the BNNT, respectively.

The root-mean-square deviation (RMSD) of the peptide was calculated to verify the changes in its conformation during the encapsulation process. The RMSD (in length units) was obtained from below Eq: ${ }^{62}$

$$
R M S D=\sqrt{\frac{\sum_{i=1}^{N} d_{i}^{2}}{N}}
$$

where $d_{i}$ is the distance between atom $i$ in the two structures, and $\mathrm{N}$ is the total number of equivalent atoms.

To evaluate the stability of the encapsulated peptide inside BNNT, an external force was loaded on the encapsulated HA-FD-13 along the z-axis of the nanotube to pull it out from the BNNT in the direction opposite to the penetrating process. The spring constant $\mathrm{k}$ and pulling velocity were chosen equal to $15 \mathrm{kcal} \mathrm{mol}^{-1} \dot{\mathrm{A}}^{-2}$ and $0.005 \dot{\mathrm{A}} \mathrm{ps}^{-1}$, respectively. ${ }^{63}$ The pulling process was simulated ten times to compute the potential of mean force profile (PMF) using Jarzynski's equality as below: ${ }^{58}$

$$
e^{-\beta \Delta G}=e^{-\beta W}
$$

where $\Delta \mathrm{G}$ and $\mathrm{W}$ correspond to the free energy discrepancy between two states and the performed work on the 
system, respectively. $\beta$ is equal to $\left(K_{B} \mathrm{~T}\right)^{-1}$ where $K_{B}$ stands for the Boltzmann constant.

2) At the second step, the release behavior of the encapsulated peptide from the $\operatorname{BNNT}(20,20)$ using the BNNT $(14,14)$, having a diameter of $18.52 \AA$ was verified. The BNNT $(14,14)$ was placed at the initial distance of 2 $\dot{A}$ from the BNNT $(20,20)$, which acted as a piston pushing out the peptide from BNNT $(20,20)$. The axial directions of nanotubes were parallel to the z-axis of the simulation box. The minimization of the system was done in the NVT ensemble at $300 \mathrm{~K}$ while nanotubes were fixed. Then, the MD run was performed in the NPT ensemble for $0.15 \mathrm{~ns}$ with the time step of $1 \mathrm{fs}$. The vdW interaction between the BNNT $(20,20)$ and the BNNT $(14,14)$ was computed as below: ${ }^{61}$

$$
\begin{aligned}
E_{v d W-i n t}(t)= & E_{B N N T(2020)+B N N T(1414)}(t)-\mathrm{E}_{B N N T(2020)}(t) \\
& -E_{B N N T(1414)}(t)
\end{aligned}
$$

Where $E_{v d W-i n t}$ refers to vdW energy between BNNT $(20,20)$ and $\operatorname{BNNT}(14,14), E_{B N N T(2020)+B N N T(1414)}$ is $\mathrm{vdW}$ interaction of BNNT $(20,20)$ combined with BNNT $(14,14) . E_{B N N T(2020)}$ and $E_{B N N T(1414)}$ stand for vdW energies of BNNT $(20,20)$ and the BNNT $(14,14)$, respectively.

\section{Results and Discussion \\ Localization of the Peptide HA-FD-I 3 Within the BNNT-Peptide Complex}

The insertion process of the peptide HA-FD-13 inside the cavity of BNNT $(20,20)$ was verified through the MD simulation. The snapshots of this process were captured using VMD software to show the peptide positions at various times in the simulation box (Figure 1). As shown in Figure 1, the peptide HA-FD-13 was successfully encapsulated inside the BNNT; however, it experienced a slower insertion process during the period of $0.2 \mathrm{~ns} 1.8 \mathrm{~ns}$ of simulation time in which half of the peptide was inside the BNNT. This occurred due to the ability of the peptide to self-adjust to pass the maximum energy barrier in the vicinity of the nanotube. Moreover, the peptide remained stably encapsulated through the $\pi-\pi$ interaction as a kind of vdW interaction between the conjugated aromatic rings of the peptide and the interior walls of the nanotube up to the end of the simulation time (15 ns).

Figure 2A represents the normalized center of mass (CoM) distance between the peptide HA-FD-13 and the BNNT $(20,20), d / d_{0}$, as a function of simulation time. The sudden two-step decrease of the $d / d_{0}$ value from 1 to 0.2 at the beginning of the simulation up to $1.8 \mathrm{~ns}$ showed that the peptide was immediately under the influence of the vdW

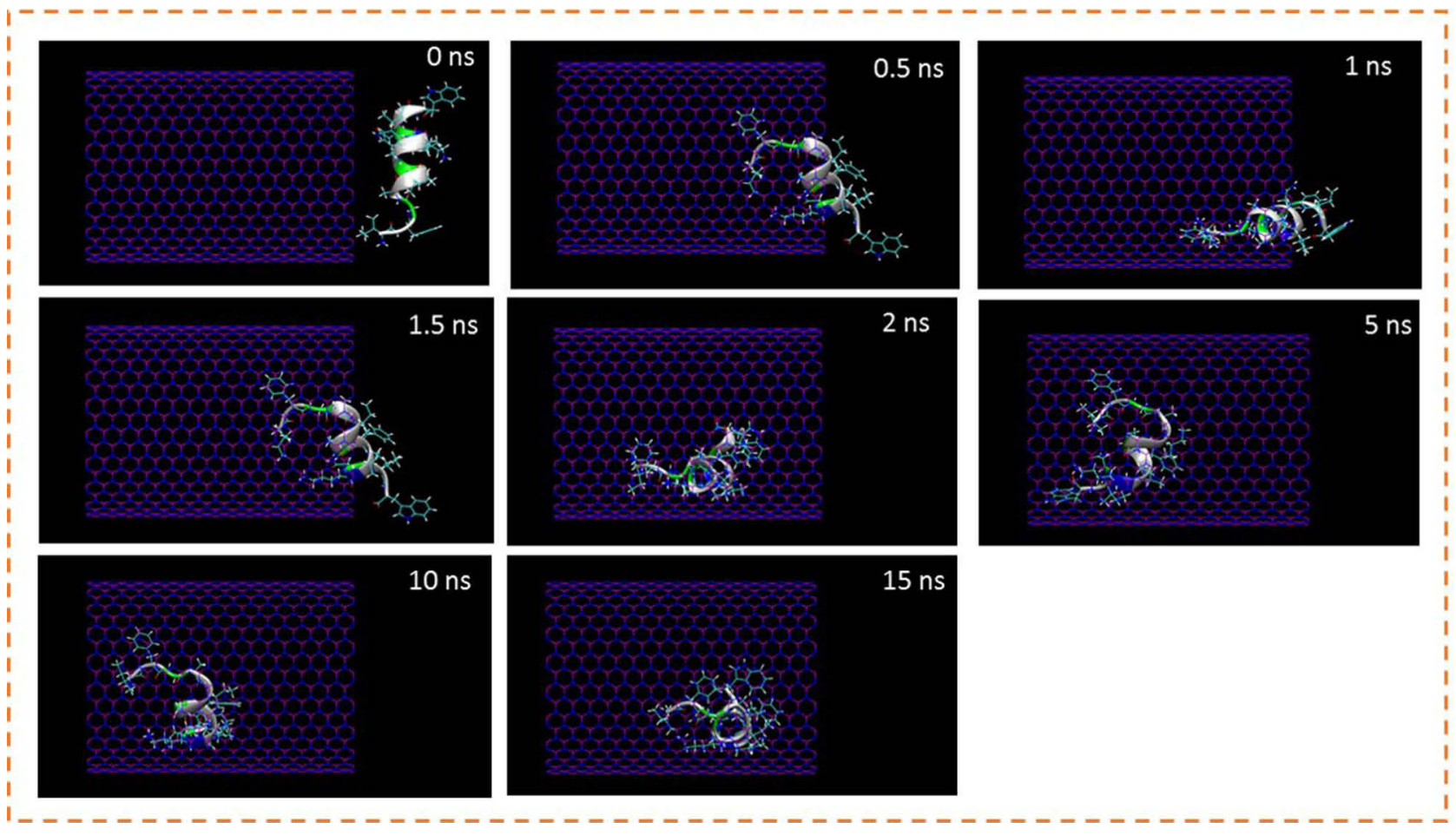

Figure I Representative snapshots of insertion of the peptide HA-FD-I3 into an armchair $(20,20)$ BNNT at various times. For clarity, molecules of water have not been shown. 

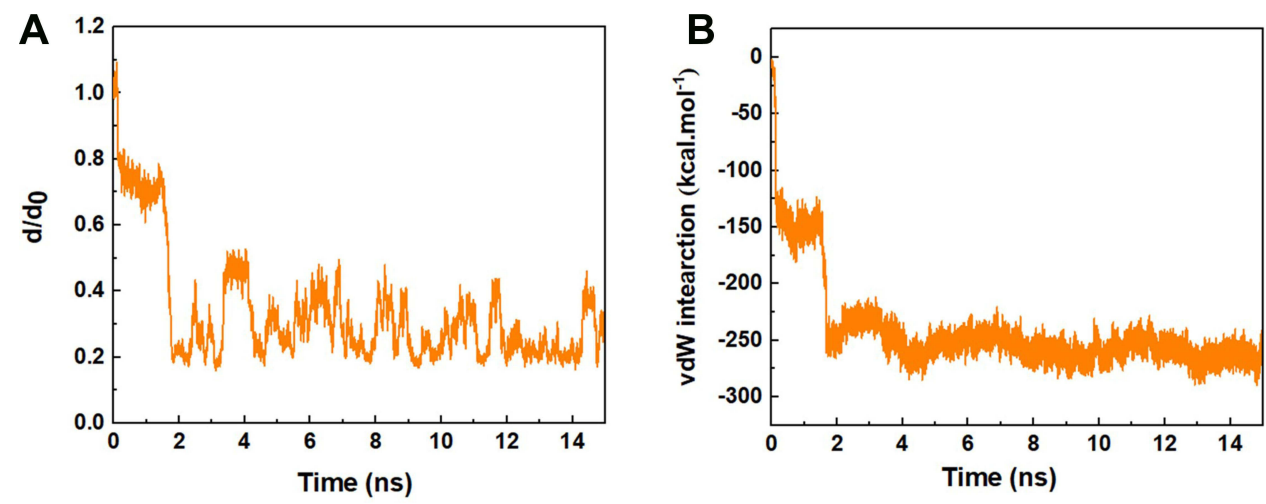

Figure $2(\mathbf{A}) d / d_{0}$ (normalized CoM distance where $d_{0}$ is the initial CoM distance) between the peptide HA-FD-13 and BNNT as a function of simulation time, (B) vdW interaction between the peptide HA-FD-I3 and the BNNT $(20,20)$ as a function of simulation time.

interaction between the peptide and the BNNT, which subsequently caused the peptide adsorption toward the cavity of the nanotube. The negligible change in the value of the $d / d_{0}$ during the period between the $0.2 \mathrm{~ns}$ and $1.8 \mathrm{~ns}$ corresponded to the self-adjusting of the peptide residues to pass the energy barrier illustrated in Figure 1. A similar decreasing trend in the value $\mathrm{d} / \mathrm{d} 0$ at the beginning of the simulation was reported in work performed by Kang et al. ${ }^{63}$ They observed that the protein SmtA experienced the conformational variations to be self-adjusted before entering the carbon nanotube (CNT). After the complete encapsulation of the peptide HA-FD-13 inside the BNNT at 2 ns, the normalized CoM distance between the peptide and the BNNT fluctuated around the specified range of $0.2-0.5$ up to the end of the simulation at $15 \mathrm{~ns}$ which revealed the stability of the confined peptide inside the nanotube.

In accordance with the neutralized nature of the BNNT $(20,20)$, it was concluded that the value of electrostatic interactions such as dipole-dipole and hydrogen bonding interactions between the BNNT and the peptide was obtained zero. Hence, the vdW interaction energy was considered as adsorbance energy of the peptide HA-FD-13 inside the BNNT. As can be observed in Figure 2B, the vdW interaction energy between the peptide and the BNNT dwindled dramatically in two steps: first, it was decreased from the value of $0 \mathrm{kcal} \cdot \mathrm{mol}^{-1}$ to the approximate value of $-150 \mathrm{kcal} \cdot \mathrm{mol}^{-1}$ at initial $0.2 \mathrm{~ns}$ of the simulation, after the plateau in vdW energy value for the duration of 1.6 $\mathrm{ns}$, for the second decrease, the $\mathrm{vdW}$ interaction energy dropped to the value of $-270 \mathrm{kcal} \cdot \mathrm{mol}^{-1}$. The observed plateau in the curve of vdW energy was in excellent agreement with the changes in the value of $\mathrm{d} / \mathrm{d} 0$ where half of the peptide was inside the BNNT, and it did not move towards the cavity of the nanotube, and subsequently, the peptide-
BNNT vdW interaction energy was not significantly varied for the duration of $1.6 \mathrm{~ns}$. In other words, the presence of barrier energy arising from the higher accumulation of hydrogen bonding networks in the vicinity of the BNNT led to the $1.6 \mathrm{~ns}$ pause in the encapsulation process. A similar energy barrier in the vicinity of the BNNT is observed in our previous work in which the encapsulation of the peptide cRW3 into the BNNT is investigated. ${ }^{42}$ After completing the peptide encapsulation, the vdW energy between the peptide and the BNNT fluctuated smoothly in the minimum specified range due to the higher $\pi-\pi$ interaction between the conjugated aromatic rings of the peptide and the interior walls of the BNNT. The decreasing trend observed for the encapsulation process of the drug inside BNNT has been similarly reported by Mehrjouei et al. ${ }^{46}$ They reported that the vdW energy between the Cisplatin and BNNT decreased and reached the value of -2282 $\mathrm{kJ} \cdot \mathrm{mol}^{-1}$ at the end of the simulation.

\section{Calculation of the Free Energy by MD Simulation}

After the completion of the simulation, when the peptide HA-FD-13 was completely inserted in the cavity of BNNT $(20,20)$ at $15 \mathrm{~ns}$, the PMF profile of the confined peptide was computed by pulling it out using the MD simulation at the speed of $0.005 \dot{\mathrm{A}} \mathrm{ps}^{-1}$, which was chosen in accordance with the speed of the encapsulation process. This simulation was repeated five times to obtain the average value of work (W) at each pulling distance, depicted as a PMF curve in Figure 3. Moreover, the peptide positions along the z-axis of the BNNT are illustrated in this Figure As shown, the free energy of this simulated system increased during the pulling distance and reached the maximum value of 200.12 $\mathrm{kcal} \cdot \mathrm{mol}^{-1}$ at $24 \AA$. This increasing trend of the PMF 


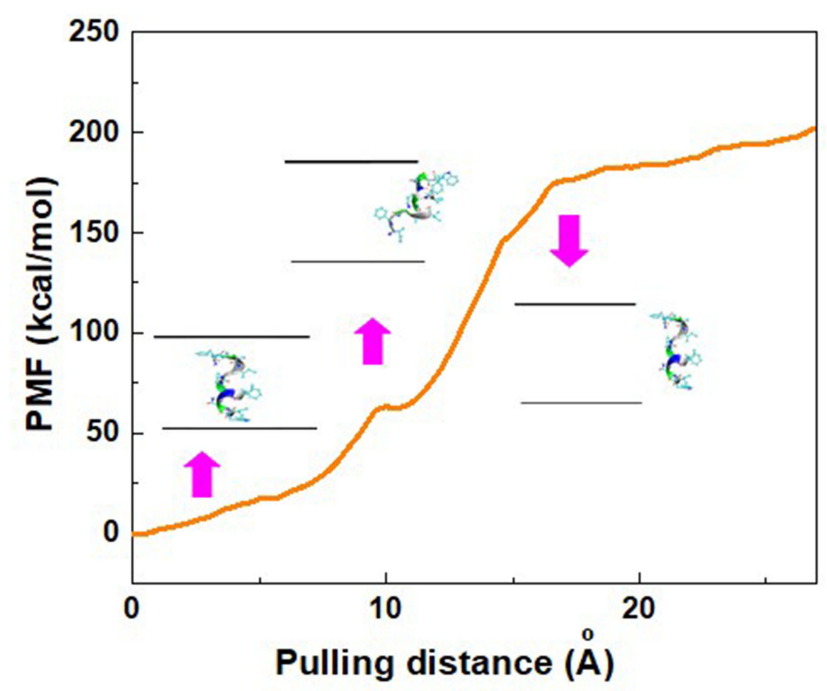

Figure 3 Potential of mean force (PMF) for the system of BNNT-peptide computed from five pullings through the $M D$ simulation. The images represent that the positions of the peptide HA-FD-I3 correspond to the z-coordinate along the BNNT at some key position. Pink arrows connect the exact position of the peptide with corresponding pulling distance.

showed that the encapsulation process of the peptide into the BNNT was a spontaneous phenomenon with a free energy of $-200.12 \mathrm{kcal} \cdot \mathrm{mol}^{-1}$. A similar spontaneous process was reported in work performed by Veclani and Melchior. ${ }^{64}$ They calculated the free energy value of $-9.5 \mathrm{Kcal} \cdot \mathrm{mol}^{-1}$ for the adsorption of the ciprofloxacin on the surface of CNTs. As another proof, the protein SmtA has been inserted into BNNT $(28,28)$ with the free energy of $-160 \mathrm{~kJ} \cdot \mathrm{mol}^{-1}$ in previous work. $^{33}$

As another observation, the PMF did not experience the significant changes and remained plateau at the pulling distance higher than $24 \AA$ when the peptide was out of the BNNT. It can be explained that, at a pulling distance higher than $24 \AA$, when the distance between the CoM of the peptide and the entrance of the BNNT was higher than the cutoff distance (12 $\AA$ ), the effect of the vdW interaction between the BNNT disappeared so that the displacement of the peptide to the higher distances did not affect the value of the PMF and free energy. The revealed small peak at the pulling distance of $10 \AA$, when half of the peptide was in the BNNT, was due to the energy barrier present in the vicinity of the BNNT.

According to the definition of the free energy of the hole system containing water molecules, BNNT $(20,20)$ and drug Isatin $(\Delta \mathrm{G}=\Delta \mathrm{H}-\mathrm{T} \Delta \mathrm{S}$ where $\Delta \mathrm{H}$ and $\Delta \mathrm{S}$ are the variations of total enthalpy and total entropy, respectively), it was observed that the value of $-\mathrm{T} \Delta \mathrm{S}$ equaled to $\Delta \mathrm{G}-\Delta \mathrm{H}=$ $-200.12-(-1818.28)=1618.16 \mathrm{kcal} \cdot \mathrm{mol}^{-1}$. Therefore, it can be concluded that the encapsulation process was an enthalpy-driven phenomenon due to the greater contribution of the enthalpy change to the free energy of the whole system while the decrement of the entropy value during the encapsulation process. ${ }^{65}$

\section{The Time-Dependent Conformation of the Peptide HA-FD-I 3}

The variations in the conformation of the peptide HA-FD -13 at 0 and $15 \mathrm{~ns}$ of the MD simulation are depicted in Figure 4A. The left image of Figure 4 is related to the immersed peptide in an aqueous solution in its natural conformation at $0 \mathrm{~ns}$. The right image corresponds to the state in which the peptide conformation was adjusted to the interior wall of the BNNT at 15 ns. Similar rearrangement and alteration in the conformation of the confinement drug doxorubicin inside the CNTs with various chirality and diameters were reported by Zhang et al. ${ }^{66}$

The root mean square deviation (RMSD) relating to the changes in the conformation of peptide HA-FD-13 in BNNT $(20,20)$ as a function of simulation time is demonstrated in Figure 4B. As observed in this figure, the RMSD varied significantly by $0.2 \mathrm{~ns}$, revealing that the peptide conformation variations are influenced by the high peptide-BNNT vdW interaction. Then, for the duration of $1.6 \mathrm{~ns}$, the RMSD did not significantly vary, which shows that not only did the peptide not experience the intense conformational changes, but also it did not move towards the BNNT. After this duration, when the peptide was inserted inside the BNNT, the value of RMSD fluctuated in the specified range so that the aromatic rings of the peptide can be placed parallel to the interior wall of the BNNT, causing the strong $\pi-\pi$ stacking interaction. A similar structural variation during the encapsulation of the ssDNA oligomer inside the CNT was observed by Shen et al. ${ }^{67}$ They observed that the value of RMSD of the biomolecule slightly fluctuated, resulting in the creation of the $\pi-\pi$ stacking interaction after complete encapsulation. In another work, ${ }^{68}$ they reported that the variations in RMSD for the encapsulated biomolecule occurred due to the different affinities of hydrophobic and the hydrophilic residues to the solvent and the nanotube, respectively. In two works done by Raffaini and Ganazzoli, ${ }^{69,70}$ they reported that the conformation of the encapsulated oligopeptide adjusted to the inner wall of the single wall CNT. 

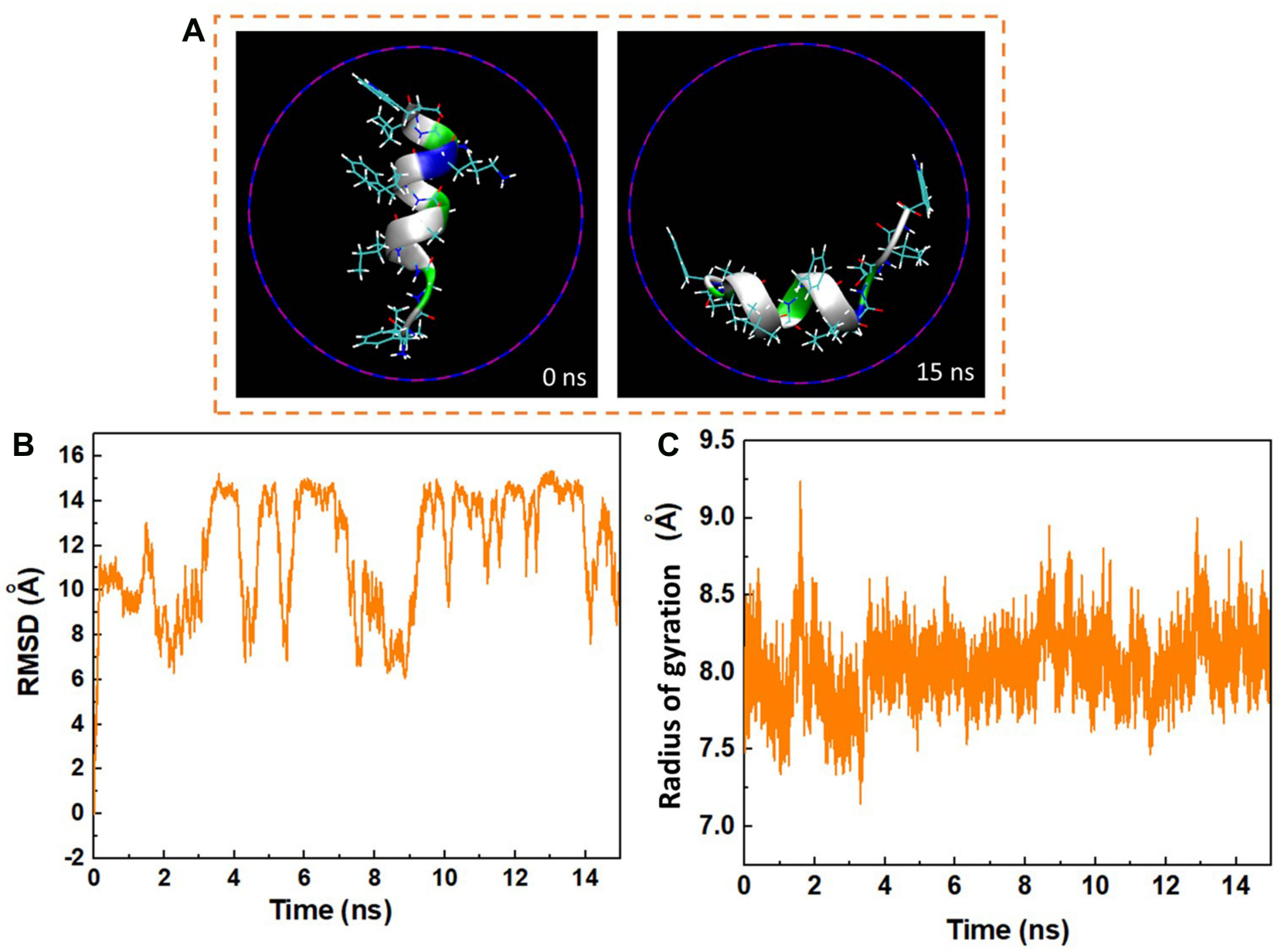

Figure 4 (A) Axial views of the peptide HA-FD-I 3 at 0 ns and I5 ns in the MD simulation. For the sake of clarity, molecules of water have not been shown. (B) Root mean square deviation (RMSD) of the peptide HA-FD-I3 as a function of simulation time. (C) Radius gyration of the peptide HA-FD- 13 as a function of simulation time in the BNNT/HA-FD-I3 complex.

In addition to RMSD values, the alteration of the gyration radius of the peptide HA-FD-13 during the encapsulation process provides beneficial details about the peptide's structural changes. Figure $4 \mathrm{C}$ shows the alteration of the gyration radius of the peptide during the simulation time. As observed, the peptide's gyration radius varied continuously in the range of 7-9 $\AA$ due to the strong peptide-BNNT vdW interaction as the simulation started.

The alterations in the distance between the CoM of the peptide HA-FD-13 and the central axis of the BNNT as a function of simulation time are represented in Figure 5A. As seen, the peptide in the simulation box was situated in a position so that the CoM of the peptide was adjusted on the central axis of the BNNT at the beginning of the simulation. After initiation of the simulation, the peptide moved toward one side of the BNNT resulted in the immediate enhancement of the peptide-axis distance to the value of $9 \AA$. This sudden movement was attributed to the strong $\mathrm{vdW}$ interaction between the BNNT wall and the peptide. However, this conformation was not permanent and altered through the peptide's adsorption to the other side wall of the nanotube as a sudden drop of the peptide-axis distance. After the complete self-insertion of the peptide in BNNT, the distance between the CoM of the peptide and the central axis of the nanotube slightly fluctuated, which showed the stability of the peptide in nanotube due to peptide-BNNT vdW interaction.

Figure 5B shows the alteration in the potential energy of the peptide HA-FD-13 during the procedure of encapsulation into the BNNT. It was seen that the potential energy of the peptide decreased, which was in favor of the self-insertion of the peptide. Moreover, the continuous fluctuation of the potential energy in the range from $-50 \mathrm{Kcal} \cdot \mathrm{mol}^{-1}$ to $50 \mathrm{Kcal} \cdot \mathrm{mol}^{-1}$ for encapsulated peptide was due to and continuous conformational changes of the peptide in the cavity of the nanotube under the effect of $\mathrm{vdW} .^{63}$ 

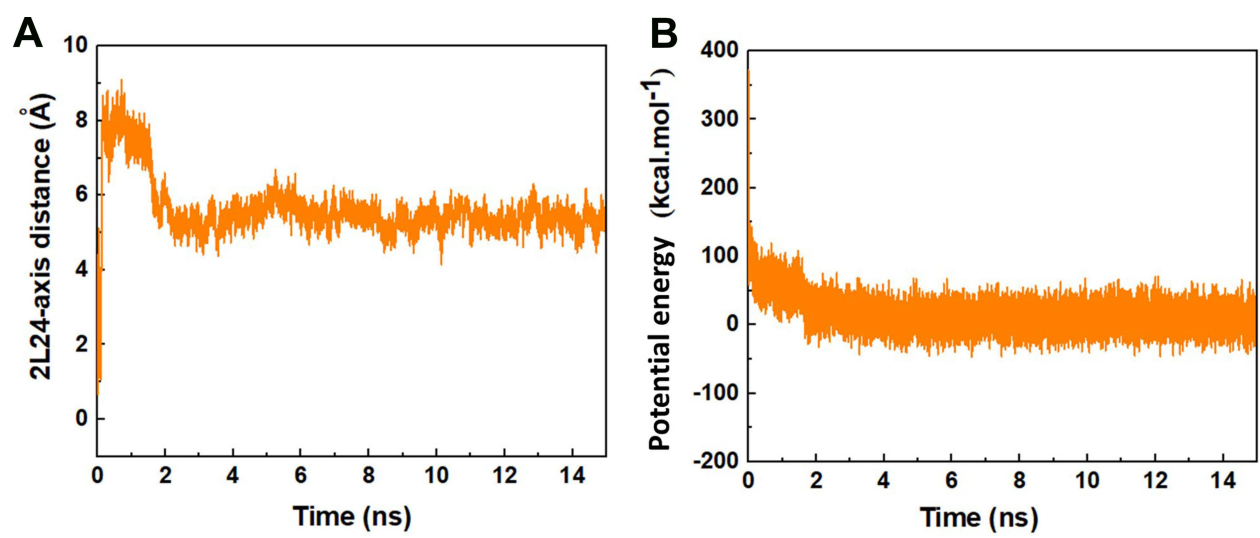

Figure 5 (A) The distance between the CoM of the peptide HA-FD-I3 and the central axis of BNNT as a function of simulation time. (B) The potential energy of the peptide HA-FD-I3 in the BNNT-peptide complex as a function of simulation time.

\section{The Release of the Encapsulated Peptide HA-FD-I 3 Using the BNNT $(|4| 4$,}

Besides the stability of the encapsulated peptide, the release of the encapsulation process is another key parameter to evaluate the nano-based drug delivery system. Therefore, the release of the encapsulated peptide HA-FD-13 from the BNNT $(20,20)$ using the BNNT $(14,14)$ was simulated. Figure 6 demonstrates the snapshots of the release process at various simulation times. The BNNT $(14,14)$ was situated at a distance of $2 \AA$ from the BNNT $(20,20)$ to adjust their z-axis. It can be observed that, as the BNNT $(14,14)$ started to enter into the BNNT $(20,20)$, the peptide was released so that the release process was completed at 83.8 ps. This observation confirmed that the $\mathrm{vdW}$ interaction between the BNNT $(14,14)$ and BNNT $(20,20)$ was stronger than between BNNT $(20,20)$ and the peptide so that the BNNT $(14,14)$ could act as a piston pushing the peptide outside the BNNT $(20,20)$. Moreover, when the encapsulated peptide was released its structure changed to the initial conformation $(\alpha$-Helix) in the absence of CNT. This means that once this peptide was released, it could serve as an antibiotic.
The changes of CoM distance between the peptide HAFD-13 and BNNT $(20,20)$, peptide HA-FD-13 and BNNT $(14,14)$, BNNT $(20,20)$, and BNNT $(14,14)$ as a function of simulation time are depicted in Figure 7A. Expectedly, by entering the BNNT $(14,14)$ into the BNNT $(20,20)$, their CoM was adjusted. The curves of the CoM distances between the peptide and both nanotubes overlapped. Moreover, the CoM distance between the BNNT $(20,20)$ and BNNT $(14,14)$ decreased dramatically to the value of zero. The changes of vdW energies between the BNNT $(20,20)$ and $(14,14)$ during the simulation are illustrated in Figure 7B. The sudden drop of the vdW energy between nanotubes to the value of the $-1300 \mathrm{Kcal} \cdot \mathrm{mol}^{-1}$ is in excellent agreement with the self-insertion of the BNNT $(14,14)$ into the BNNT $(20,20)$ and subsequently release of the peptide.

\section{Conclusion}

In summary, the encapsulation process of the antimicrobial peptide HA-FD-13 with the ID code of 2124 inside the BNNT $(20,20)$ was studied, followed by the release
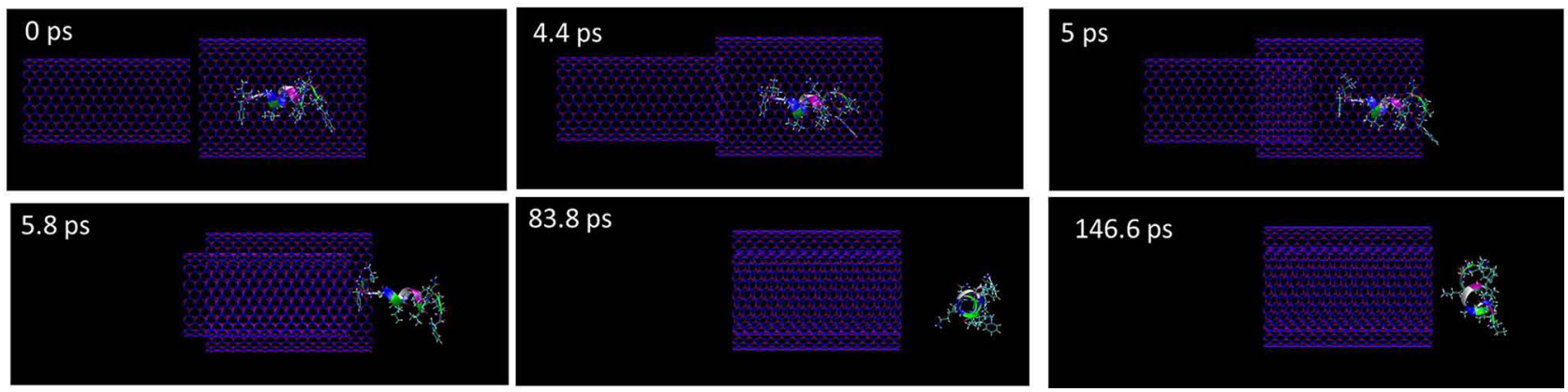

Figure 6 Representative snapshots of the release of the encapsulated peptide HA-FD-I3 using an armchair $(14,14)$ BNNT at various times. For clarity, molecules of water have not been shown. 
A

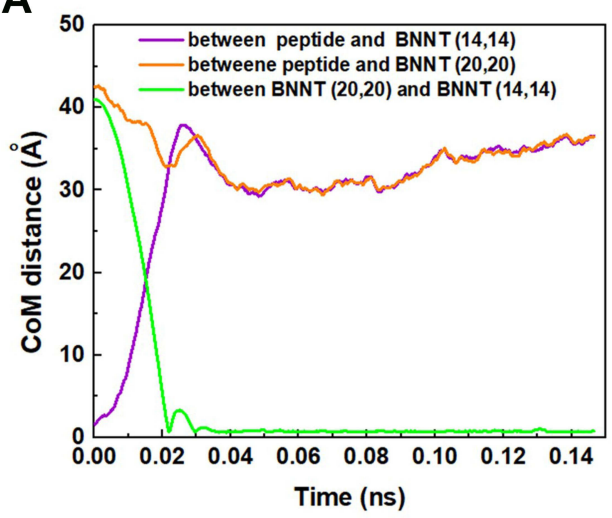

B

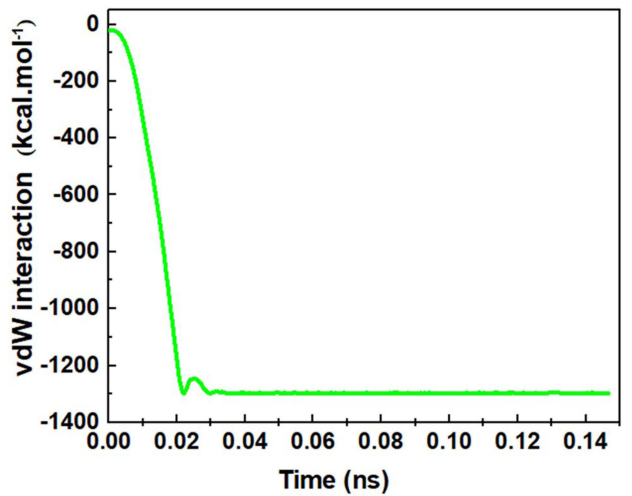

Figure 7 (A) the changes of CoM distance between the peptide HA-FD-I3 and BNNT $(20,20)$, peptide HA-FD-13 and BNNT (I4, I4), BNNT (20,20) and BNNT (I4,I4), (B) vdW interaction energy between the BNNT $(14,14)$ and BNNT $(20,20)$ as a simulation time.

behavior of the encapsulated peptide using the BNNT $(14,14)$ and by employing the molecular dynamics simulation. It was observed that the peptide-BNNT $(20,20)$ van der Waals (vdW) interaction energy and the normalized center of mass (CoM) distance between the peptide and the BNNT $\left(d / d_{0}\right)$ dwindled to the values of the -270 $\mathrm{kcal} \cdot \mathrm{mol}^{-1}$ and 0.3 , respectively, at the end of the simulation (15 ns). However, during the period of $0.2-1.8 \mathrm{~ns}$, when half of the peptide was inside the nanotube, the encapsulation process was paused due to the energy barrier in the vicinity of the BNNT and subsequently the selfadjustment of the peptide. The obtained negative value of $-200.12 \mathrm{kcal} \cdot \mathrm{mol}^{-1}$ for free energy confirmed that the insertion procedure occurred spontaneously. The changes of the root mean square deviation (RMSD) showed that for the duration of $1.6 \mathrm{~ns}$, not only did the peptide not experience the intense conformational changes, it also did not move toward the BNNT. After the peptide's complete encapsulation, the value of RMSD fluctuated in the specified range so that the aromatic rings of the peptide situated parallel to the interior wall of the BNNT causing the strong $\pi-\pi$ stacking interaction. The decreasing trend of the peptide's potential energy was in favor of the self-insertion of the peptide inside the BNNT. In terms of the peptide release, it was observed that, as the BNNT $(14,14)$ started to enter into the BNNT $(20,20)$, the peptide was released so that the release process was completed at 83.8 ps. Moreover, the sudden drop of the vdW energy between nanotubes to the value of the $-1300 \mathrm{Kcal} \cdot \mathrm{mol}^{-1}$ is in great agreement with the self-insertion of the BNNT $(14,14)$ into the BNNT $(20,20)$ and subsequently release of the peptide.

\section{Disclosure}

The authors report no conflicts of interest in this work.

\section{References}

1. Bodanszky M. Peptide Chemistry. Berlin, Germany: Springer-Verlag; 1993.

2. Mondal S, Das S, Nandi AK. A review on recent advances in polymer and peptide hydrogels. Soft Matter. 2020;16:1404-1454.

3. Powers J-PS, Hancock RE. The relationship between peptide structure and antibacterial activity. Peptides. 2003;24(11):1681-1691. doi:10.1016/j.peptides.2003.08.023

4. Tamerler C, Sarikaya M. Genetically designed peptide-based molecular materials. Acs Nano. 2009;3(7):1606-1615. doi:10.1021/ $\mathrm{nn} 900720 \mathrm{~g}$

5. Knorr R, Trzeciak A, Bannwarth W, Gillessen D. New coupling reagents in peptide chemistry. Tetrahedron Lett. 1989;30 (15):1927-1930. doi:10.1016/S0040-4039(00)99616-3

6. Kuzmicheva G, Belyavskaya V. Peptide phage display in biotechnology and biomedicine. Biochem (Mosc) Suppl Ser B Biomed Chem. 2017;11(1):1-15. doi:10.1134/S1990750817010061

7. De La Rica R, Matsui H. Applications of peptide and protein-based materials in bionanotechnology. Chem Soc Rev. 2010;39 (9):3499-3509. doi:10.1039/b917574c

8. Kuzmicheva G, Belyavskaya V. Peptide phage display in biotechnology and biomedicine. Biomed Khim. 2016;62(5):481-495. doi:10.18097/PBMC20166205481

9. Fosgerau K, Hoffmann T. Peptide therapeutics: current status and future directions. Drug Discov Today. 2015;20(1):122-128. doi:10.1016/j.drudis.2014.10.003

10. Honigberg MC, Chang L-S, McGuire DK, Plutzky J, Aroda VR, Vaduganathan M. Use of glucagon-like peptide-1 receptor agonists in patients with type 2 diabetes and cardiovascular disease: a review. JAMA Cardiol. 2020;5(10):1182-1190. doi:10.1001/ jamacardio.2020.1966

11. Shahidi F, Zhong Y. Bioactive peptides. J AOAC Int. 2008;91 (4):914-931. doi:10.1093/jaoac/91.4.914

12. Daliri EB-M, Oh DH, Lee BH. Bioactive peptides. Foods. 2017;6 (5):32. doi:10.3390/foods6050032

13. Wang P, Cui Q, Zhang Y, et al. A review of pedal peptide/orcokinin-type neuropeptides. Curr Protein Pept Sci. 2021;22(1):41-49. doi:10.2174/1389203721666201109112758 
14. Liu W-P, Chen Y-H, Ming X, Kong Y. Design and synthesis of a novel cationic peptide with potent and broad-spectrum antimicrobial activity. Biomed Res Int. 2015;2015:578764. doi:10.1155/2015/ 578764

15. Yeaman MR, Yount NY. Mechanisms of antimicrobial peptide action and resistance. Pharmacol Rev. 2003;55(1):27-55. doi:10.1124/ pr.55.1.2

16. Mukhopadhyay S, Prasad AB, Mehta CH, Nayak UY. Antimicrobial peptide polymers: no escape to ESKAPE pathogens-a review. World J Microbiol Biotechnol. 2020;36(9):1-14. doi:10.1007/s11274-02002907-1

17. Hitchner MA, Santiago-Ortiz LE, Necelis MR, et al. Activity and characterization of a $\mathrm{pH}$-sensitive antimicrobial peptide. Biochim Biophys Acta. 2019;1861(10):182984. doi:10.1016/j.bbamem.20 19.05.006

18. Jenssen H, Hamill P, Hancock RE. Peptide antimicrobial agents. Clin Microbiol Rev. 2006;19(3):491-511. doi:10.1128/CMR.00056-05

19. Gough M, Hancock R, Kelly NM. Antiendotoxin activity of cationic peptide antimicrobial agents. Infect Immun. 1996;64(12):4922-4927. doi:10.1128/IAI.64.12.4922-4927.1996

20. Lei J, Sun L, Huang S, et al. The antimicrobial peptides and their potential clinical applications. Am J Transl Res. 2019;11(7):3919.

21. Moravej H, Moravej Z, Yazdanparast M, et al. Antimicrobial peptides: features, action, and their resistance mechanisms in bacteria Microb Drug Resist. 2018;24(6):747-767. doi:10.1089/ mdr.2017.0392

22. Pardridge WM. Recent developments in peptide drug delivery to the brain. Pharmacol Toxicol. 1992;71(1):3-10. doi:10.1111/j.16000773.1992.tb00512.x

23. Pizzolato-Cezar LR, Okuda-Shinagawa NM, Machini MT. Combinatory therapy antimicrobial peptide-antibiotic to minimize the ongoing rise of resistance. Front Microbiol. 2019;10:1703. doi: $10.3389 /$ fmicb. 2019.01703

24. Subbalakshmi C, Bikshapathy E, Sitaram N, Nagaraj R. Antibacterial and hemolytic activities of single tryptophan analogs of indolicidin. Biochem Biophys Res Commun. 2000;274(3):714-716. doi:10.1006/ bbrc. 2000.3214

25. Band VI, Weiss DS. Mechanisms of antimicrobial peptide resistance in gram-negative bacteria. Antibiotics. 2015;4(1):18-41. doi:10.3390/ antibiotics 4010018

26. Smith AW. Biofilms and antibiotic therapy: is there a role for combating bacterial resistance by the use of novel drug delivery systems? Adv Drug Deliv Rev. 2005;57(10):1539-1550. doi:10.1016/j. addr.2005.04.007

27. Zarrintaj P, Ramsey JD, Samadi A, et al. Poloxamer: a versatile tri-block copolymer for biomedical applications. Acta Biomater. 2020.

28. Yoosefian M, Etminan N. Density functional theory (DFT) study of a new novel bionanosensor hybrid; tryptophan/Pd doped single walled carbon nanotube. Physica E Low Dimens Syst Nanostruct. 2016;81:116-121. doi:10.1016/j.physe.2016.03.009

29. Skandani AA, Al-Haik M. Reciprocal effects of the chirality and the surface functionalization on the drug delivery permissibility of carbon nanotubes. Soft Matter. 2013;9(48):11645-11649. doi:10.1039/ C3SM52126E

30. Ramos MADS, Da Silva PB, Spósito L, et al. Nanotechnology-based drug delivery systems for control of microbial biofilms: a review. Int J Nanomedicine. 2018;13:1179. doi:10.2147/IJN.S146195

31. Bernkop-Schnürch A, Bratengeyer I, Valenta C. Development and in vitro evaluation of a drug delivery system protecting from trypsinic degradation. Int J Pharm. 1997;157(1):17-25. doi:10.1016/S03785173(97)00198-1

32. Arsawang U, Saengsawang O, Rungrotmongkol T, et al. How do carbon nanotubes serve as carriers for gemcitabine transport in a drug delivery system? J Mol Graph Model. 2011;29(5):591-596. doi:10.1016/j.jmgm.2010.11.002
33. Zarghami MD, Bagheri B, Nasiriasayesh A, et al. Insight into the self-insertion of a protein inside the boron nitride nanotube. ACS Omega. 2020;5(49):32051. doi:10.1021/acsomega.0c05080

34. Chen X, Wu P, Rousseas $\mathrm{M}$, et al. Boron nitride nanotubes are noncytotoxic and can be functionalized for interaction with proteins and cells. J Am Chem Soc. 2009;131(3):890-891. doi:10.1021/ ja $807334 \mathrm{~b}$

35. Cohen ML, Zettl A. The physics of boron nitride nanotubes. Phys Today. 2010;63(11):34-38. doi:10.1063/1.3518210

36. Mirhaji E, Afshar M, Rezvani S, Yoosefian M. Boron nitride nanotubes as a nanotransporter for anticancer docetaxel drug in water/ ethanol solution. J Mol Liq. 2018;271:151-156. doi:10.1016/j. molliq.2018.08.142

37. Khatti Z, Hashemianzadeh SM. Boron nitride nanotube as a delivery system for platinum drugs: drug encapsulation and diffusion coefficient prediction. Eur J Pharm Sci. 2016;88:291-297. doi:10.1016/j. ejps.2016.04.011

38. Roosta S, Nikkhah SJ, Sabzali M, Hashemianzadeh SM. Molecular dynamics simulation study of boron-nitride nanotubes as a drug carrier: from encapsulation to releasing. RSC Adv. 2016;6 (11):9344-9351. doi:10.1039/C5RA22945F

39. Mortazavifar A, Raissi H, Shahabi M. Comparative prediction of binding affinity of hydroxyurea anti-cancer to boron nitride and carbon nanotubes as smart targeted drug delivery vehicles. $J$ Biomol Struct Dyn. 2019;37(18):4852-4862. doi:10.1080/07391102.20 19.1567385

40. Roosta S, Hashemianzadeh SM, Ketabi S. Encapsulation of cisplatin as an anticancer drug into boron-nitride and carbon nanotubes: molecular simulation and free energy calculation. Mater Sci Eng C. 2016;67:98-103. doi:10.1016/j.msec.2016.04.100

41. Hasanzade Z, Raissi H. Carbon and boron nanotubes as a template material for adsorption of 6-Thioguanine chemotherapeutic: a molecular dynamics and density functional approach. $J$ Biomol Struct Dyn. 2020;38(3):697-707. doi:10.1080/07391102.20 19.1585951

42. Zarghami MD, Bagheri B, Yousefi F, et al. Boron nitride nanotube as an antimicrobial peptide carrier: a theoretical insight. Int J Nanomedicine. 2021;16:1837. doi:10.2147/IJN.S298699

43. Iranmanesh-Zarandy Z, Dehestani M. Molecular dynamics simulation of paracetamol drug adsorption on boron nitride nanotube: effects of temperature, nanotube length, diameter, and chirality. ChemistrySelect. 2019;4(27):7866-7873. doi:10.1002/slct.201900644

44. Sedghamiz E, Jamalizadeh E, Hosseini SMA, Sedghamiz T, Zahedi E. Molecular dynamics simulation of boron nitride nanotube as a drug carrier. Arab J Sci Eng. 2014;39(9):6737-6742. doi:10.1007/s13369-014-1228-y

45. El Khalifi M, Bentin J, Duverger E, Gharbi T, Boulahdour H, Picaud F. Encapsulation capacity and natural payload delivery of an anticancer drug from boron nitride nanotube. Phys Chem Chem Phys. 2016;18(36):24994-25001. doi:10.1039/C6CP01387B

46. Mehrjouei E, Akbarzadeh H, Shamkhali AN, Abbaspour M, Salemi S, Abdi P. Delivery of cisplatin anticancer drug from carbon, boron nitride, and silicon carbide nanotubes forced by Ag-nanowire: a comprehensive molecular dynamics study. Mol Pharm. 2017;14 (7):2273-2284. doi:10.1021/acs.molpharmaceut.7b00106

47. Saikia N, Jha AN, Deka RC. Interaction of pyrazinamide drug functionalized carbon and boron nitride nanotubes with pncA protein: a molecular dynamics and density functional approach. RSC Adv. 2013;3(35):15102-15107. doi:10.1039/c3ra42534g

48. Katiyar RS, Jha PK. Molecular simulations in drug delivery: opportunities and challenges. Wiley Interdiscip Rev Comput Mol Sci. 2018;8:e1358.

49. Singh A, Vanga SK, Orsat V, Raghavan V. Application of molecular dynamic simulation to study food proteins: a review. Crit Rev Food Sci Nutr. 2018;58(16):2779-2789. doi:10.1080/10408398.20 17.1341864 
50. Bagheri B, Dehaghani MZ, Karami Z, et al. Correlation between surface topological defects and fracture mechanism of $\gamma$-graphynelike boron nitride nanosheets. Comput Mater Sci. 2020;110152.

51. Dehaghani MZ, Mashhadzadeh AH, Salmankhani A, et al. Fracture toughness and crack propagation behavior of nanoscale beryllium oxide graphene-like structures: a molecular dynamics simulation analysis. Eng Fract Mech. 2020;235:107194. doi:10.1016/j. engfracmech.2020.107194

52. Zarghami dehaghani M, Salmankhani A, Hamed mashhadzadeh A, Habibzadeh S, Abida O, Reza Saeb M. Fracture mechanics of polycrystalline beryllium oxide nanosheets: a theoretical basis. Eng Fract Mech. 2021;244:107552. doi:10.1016/j.engfracmech.2021.107552

53. Bagheri B, Dehaghani MZ, Safa ME, et al. Fracture fingerprint of polycrystalline $\mathrm{C} 3 \mathrm{~N}$ nanosheets: theoretical basis. J Mol Graph Model. 2021;106:107899. doi:10.1016/j.jmgm.2021.107899

54. Salmankhani A, Karami Z, Mashhadzadeh AH, et al. A theoretical scenario for the mechanical failure of boron carbide nanotubes. Comput Mater Sci. 2021;186:110022. doi:10.1016/j.commatsci.20 20.110022

55. Albooyeh A, Dadrasi A, Mashhadzadeh AH. Effect of point defects and low-density carbon-doped on mechanical properties of BNNTs: a molecular dynamics study. Mater Chem Phys. 2020;239:122107. doi:10.1016/j.matchemphys.2019.122107

56. Zhu S, Aumelas A, Gao B. Convergent evolution-guided design of antimicrobial peptides derived from influenza A virus hemagglutinin. J Med Chem. 2011;54(4):1091-1095. doi:10.1021/jm1010463

57. Plimpton S. Fast parallel algorithms for short-range molecular dynamics. J Comput Phys. 1995;117(1):1-19. doi:10.1006/ jcph.1995.1039

58. Park S, Schulten K. Calculating potentials of mean force from steered molecular dynamics simulations. J Chem Phys. 2004;120 (13):5946-5961. doi:10.1063/1.1651473

59. Los J, Kroes J, Albe K, Gordillo R, Katsnelson M, Fasolino A. Extended tersoff potential for boron nitride: energetics and elastic properties of pristine and defective h-BN. Phys Rev B. 2017;96 (18):184108. doi:10.1103/PhysRevB.96.184108
60. Hirschfelder JO, Curtiss CF, Bird RB, Mayer MG. Molecular Theory of Gases and Liquids. New York: Wiley; 1964.

61. Humphrey W, Dalke A, Schulten K. VMD: visual molecular dynamics. J Mol Graph. 1996;14(1):33-38. doi:10.1016/02637855(96)00018-5

62. Sargsyan K, Grauffel C, Lim C. How molecular size impacts RMSD applications in molecular dynamics simulations. $J$ Chem Theory Comput. 2017;13:1518-1524.

63. Kang Y, Liu Y-C, Wang Q, Shen J-W, Wu T, Guan W-J. On the spontaneous encapsulation of proteins in carbon nanotubes. Biomaterials. 2009;30(14):2807-2815. doi:10.1016/j.biomaterials. 20 09.01.024

64. Veclani D, Melchior A. Adsorption of ciprofloxacin on carbon nanotubes: insights from molecular dynamics simulations. J Mol Liq. 2020;298:111977. doi:10.1016/j.molliq.2019.111977

65. Zhang D, Gullingsrud J, McCammon JA. Potentials of mean force for acetylcholine unbinding from the alpha7 nicotinic acetylcholine receptor ligand-binding domain. $J$ Am Chem Soc. 2006;128 (9):3019-3026. doi:10.1021/ja057292u

66. Zhang L, Peng G, Li J, et al. Molecular dynamics study on the configuration and arrangement of doxorubicin in carbon nanotubes. J Mol Liq. 2018;262:295-301. doi:10.1016/j.molliq.2018.04.097

67. Shen J-W, Tang T, Wei X-H, et al. On the loading mechanism of ssDNA into carbon nanotubes. RSC Adv. 2015;5(70):56896-56903. doi:10.1039/C5RA01941A

68. Shen J-W, Wu T, Wang Q, Kang Y. Induced stepwise conformational change of human serum albumin on carbon nanotube surfaces. Biomaterials. 2008;29(28):3847-3855. doi:10.1016/j.biomaterials.20 08.06.013

69. Raffaini G, Ganazzoli F. Surface topography effects in protein adsorption on nanostructured carbon allotropes. Langmuir. 2013;29 (15):4883-4893. doi:10.1021/la3050779

70. Raffaini G, Ganazzoli F. Separation of chiral nanotubes with an opposite handedness by chiral oligopeptide adsorption: a molecular dynamics study. J Chromatogr A. 2015;1425:221-230. doi:10.1016/j. chroma.2015.11.045
International Journal of Nanomedicine

\section{Publish your work in this journal}

The International Journal of Nanomedicine is an international, peerreviewed journal focusing on the application of nanotechnology in diagnostics, therapeutics, and drug delivery systems throughout the biomedical field. This journal is indexed on PubMed Central, MedLine, CAS, SciSearch ${ }^{\mathbb{}}$, Current Contents ${ }^{\mathbb{R}} /$ Clinical Medicine, $^{-}$

\section{Dovepress}

Journal Citation Reports/Science Edition, EMBase, Scopus and the Elsevier Bibliographic databases. The manuscript management system is completely online and includes a very quick and fair peer-review system, which is all easy to use. Visit http://www.dovepress.com/ testimonials.php to read real quotes from published authors. 